\title{
A Note on the Petroleum Industry's Participation in Conservation Agreements for the Lesser Prairie Chicken
}

\author{
Richard T. Melstrom
}

\begin{abstract}
This paper examines the petroleum industry's willingness to participate in conservation agreements for the lesser prairie chicken, a candidate for listing under the Endangered Species Act (ESA). Voluntary conservation agreements with assurances (VCAAs) can incentivize habitat conservation and sustain economic development. Using data on oil and natural gas wells in Kansas and Oklahoma, I develop a discrete choice model to examine company preferences for locating wells and participating in VCAAs for the lesser prairie chicken. Participation in VCAAs is low, but I find participating wells are concentrated in areas with the most crucial habitat.
\end{abstract}

Key Words: conservation agreements with assurances, development, discrete choice model, endangered species, oil and natural gas, wildlife

Policy alternatives to land use restrictions are needed to coordinate private conservation for imperiled species. Habitat loss is the biggest driver of extinction risks (Millennium Ecosystem Assessment 2005), so land use restrictions are an important policy instrument. However, by creating a culture of "shoot, shovel, and shut-up," in which landowners kill animals and destroy habitat to avoid regulations, land use restrictions often fail to incentivize private conservation (Innes, Polasky, and Tschirhart 1998, Shogren et al. 1999). This has prompted regulators to develop voluntary conservation agreements with assurances (VCAAs) as an alternative policy instrument. VCAAs provide landowners assurances that if they implement certain conservation practices they will not be burdened with land use restrictions or additional conservation actions in the future.

The Endangered Species Act (ESA) is the primary U.S. law protecting imperiled species. The ESA prohibits any act of harm to listed species, including habitat destruction (U.S. Fish and Wildlife Service 1999). The threat

Richard T. Melstrom is an assistant professor at the Institute of Environmental Sustainability, Loyola University Chicago. Correspondence: Richard T. Melstrom " 424 IES Hall " Loyola University Chicago - Chicago = IL 60201 - Email: rmelstrom@luc.edu

The author would like to thank the editor and two reviewers for helpful comments. Funding for this study was provided through the Federal Aid in Wildlife Restoration Program (Project F15AF01178) sponsored through the Oklahoma Department of Wildlife Conservation.

Agricultural and Resource Economics Review 48/1 (April 2019) 100-116

(C) The Author(s) 2018. This is an Open Access article, distributed under the terms of the Creative Commons Attribution-NonCommercial-ShareAlike licence (http://creativecommons.org/licenses/by-nc-sa/4.0/), which permits non-commercial re-use, distribution, and reproduction in any medium, provided the same Creative Commons licence is included and the original work is properly cited. The written permission of Cambridge University Press must be obtained for commercial re-use. 
of civil and criminal penalties for violations has made the law controversial among rural landowners and natural resource industries (Brown and Shogren 1998). However, the law provides some policy instruments to incentivize private conservation. In particular, Candidate Conservation Agreements with Assurances provide regulatory certainty to landowners who commit to certain conservation actions that benefit listing candidates (U.S. Fish and Wildlife Service 2011). Safe Harbor Agreements provide assurances that additional restrictions will not be required if the actions taken under the agreement attract listed species onto a landowner's property (U.S. Fish and Wildlife Service 2013). Both are VCAAs in that participants secure regulatory certainty in exchange for habitat conservation. Thus, imperiled species on private lands are managed through a combination of ESA land use restrictions and VCAA instruments (Boyd and Epanchin-Niell 2017).

In this paper, I analyze participation in VCAAs and the effect of ESA regulations among petroleum companies. Petroleum development has contributed to the decline of several wildlife populations in the central United States (Naugle 2011). I use the conservation program to protect the lesser prairie chicken (Tympanuchus pallidicinctus) (LPC) as an empirical example. The LPC's decline is attributed to habitat loss and fragmentation, and it relies almost entirely on private land for habitat (Hagen et al. 2004, Timmer et al. 2014). In 2013, the Western Association of Fish and Wildlife Agencies developed the Rangewide Conservation Plan (RWP) to help companies avoid LPC habitat and replace land lost to development (Van Pelt et al. 2013). Petroleum companies participate in the RWP by enrolling wells (or associated infrastructure) into a conservation agreement; in return, companies receive assurances that enrolled projects will not be subject to ESA land use restrictions in the future if the LPC is listed. This program received widespread support from industry and regulators, but it became controversial when the LPC was listed under the ESA as threatened in 2014 -a decision later vacated after a federal court determined listing was unwarranted (Wertz 2015).

This study advances research on the economics of conservation programs in two novel ways. The first is to measure the effect of habitat quality on companies' willingness to enroll location-specific projects in VCAAs. Where development occurs is important, because habitat quality can vary substantially over a landscape. The main problem motivating this study is whether or not companies distinguish high-priority from low-priority habitat when practicing conservation and, especially, enrolling in VCAAs. The LPC presents a useful case study because development projects could participate in VCAAs through the RWP, and RWP specialists conspicuously mapped four ranks of LPC habitat quality. A second contribution is showing how location and conservation preferences change over time. Petroleum companies operating in LPC habitat have viewed voluntary conservation as a way to avoid an ESA listing and onerous land use restrictions. Changes in the LPC's listing status in 2014 provide a unique quasi-experiment because regulators 
allowed companies to enroll in the RWP before and after listing. Thus, an additional empirical question is how the demand for VCAAs changed when regulators listed the LPC.

This study provides empirical measures of the petroleum industry's willingness to participate in conservation agreements. There is a large and robust literature that examines participation in habitat conservation programs. However, this paper is distinguished by its focus on companies rather than landowners (Parkhurst et al. 2002, Smith and Shogren 2002, Duke 2004, Langpap 2004, Langpap and Wu 2004, Mehmood and Zhang 2005, Langpap 2006, Reeling et al. 2007, Parkhurst and Shogren 2008, Drechsler et al. 2010, Byl 2015). Melstrom (2017) also studies the effect of ESA regulations on petroleum development but does not examine the willingness of companies to participate in VCAAs as I do here. While traditional voluntary conservation programs take place exclusively before or after listing, I am able to compare the demand for agreements before and after listing because enrollment in conservation agreements continued after regulators listed the LPC. Petroleum companies have been generally reluctant to enroll wells in conservation agreements, but discrete choice model estimates show that companies were significantly more likely to participate if they drilled wells in priority habitat after regulators listed the LPC.

\section{Background}

Petroleum companies participate in the RWP by enrolling development projects into a VCAA. ${ }^{1}$ Participating generates benefits and costs for a company. The primary benefits are regulatory assurances; there will be no legal ramifications if the project incidentally harms a LPC, if regulators eventually list the species. The industry as a whole also benefits if private conservation aids in recovering the species and regulators decide not to list. Participation costs include a mitigation fee and a commitment to avoid and/or minimize habitat impacts, such as by developing altered rather than pristine habitat and minimizing activity during the breeding season. The mitigation fee depends on ecoregion (e.g., shortgrass prairie, sand sagebrush), previous

\footnotetext{
1 The RWP offers two types of VCAAs, specifically a Candidate Conservation Agreement with Assurances (CCAA) and a Western Association of Fish and Wildlife Agencies Conservation Agreement (WCA). WCAs and CCAAs differ in a few ways. First, any company can participate in a WCA, although the CCAA is exclusively for oil and gas. Second, WCA assurances are derived from the ESA's Section 4(d) rule for threatened species, while CCAA assurances are derived under Section 10 for threatened and endangered species. Third, the CCAA enrollment period is tied to the LPC's candidate status, so companies that want to participate in the RWP after listing must enroll in a WCA. However, the obligations under each agreement are identical because both adhere to the RWP's conservation delivery system. I do not distinguish between CCAAs and WCAs because these differences are slight and because projects could have transferred from a WCA to a CCAA after the listing was vacated.
} 
development impacts, and the quality of habitat affected by the project. The RWP places habitat into four quality ranks within 10 miles of the LPC's estimated occupied range (EOR +10$)$, which are classified as focal areas, connectivity zones, other suitable habitat and unsuitable habitat. Mitigation fees tend to be highest in focal areas and lowest in unsuitable habitat. Specific mitigation actions include prohibiting participants from accessing their project sites between 3:00 am and 9:00 am March 15-July 15 to protect breeding activities and requiring fences to be marked to prevent bird collisions. Enrollments started in January 2014. Enrollments continued after regulators listed the LPC as threatened in May 2014. The listing announcement stated the decision was in part due to "uncertaint[y] concerning availability of funding and the level of voluntary participation in the rangewide plan" (U.S. Fish and Wildlife Service 2014). The Permian Basin Petroleum Association, an industry trade group, filed suit claiming that their voluntary conservation efforts and support for the RWP precluded the need to list. The suit against the listing decision was successful, and a U.S. district court vacated the listing rule in September 2015 (Wertz 2015); enrollments in the RWP continued each time the LPC gained and lost its ESA listed status.

\section{Methods}

The empirical strategy developed below is based on a conceptual model of a petroleum company's drilling location preferences. I assume that, with limited drilling resources, a company drills one location at a time. ${ }^{2}$ The expected value from location $j$ at time $t$ is

$$
v_{j t k}=p f\left(\alpha h_{j}+\beta x_{j}+\gamma z\right)-c_{j}-r z+\delta_{t} h_{j}\left(1-k_{t}\right)+\left(\kappa+\mu \mathrm{fee}_{j}+\vartheta h_{j}\right) k,
$$

where $p$ is the per unit price of oil, $f\left(0\right.$ is units of oil produced from the well, $h_{j}$ are fixed habitat attributes, $x_{j}$ are other location attributes, $z$ are variable inputs, $c_{j}$ is a location-specific cost, $r$ is the marginal cost of the variable inputs, and $\kappa+$ fee $_{j}$ is the fixed plus location-specific cost of enrolling a well in the RWP. The variable $k$ equals one if the well is enrolled and zero otherwise. The variables $\mathrm{fee}_{j}$ is the cost of mitigating for location $j$, which depends on ecoregion characteristics, prior impacts, and habitat quality. The fourth righthand side term measures the penalty from ESA regulations that occur at time $t$. The last term measures the relative cost of enrolling in the RWP. Solving the first order condition for variable inputs shows that optimal output (oil production) depends only on location choice, conditional on $k$. The decision to enroll in the RWP, which is determined jointly with the preferred drilling

\footnotetext{
2 This is almost certainly true for all but the largest companies. Relaxing this assumption would require a model that goes beyond the scope of this paper.
} 
location, therefore depends on location attributes. This decision can be modeled econometrically in a discrete choice framework.

The analysis uses three periods: (1) the time before the RWP, (2) during the RWP when the LPC is not listed, and (3) during the RWP when the LPC is listed. The first period occurs prior to December 2013, when the RWP was launched, and the third period runs from May 2014 to September 2015. First- and secondperiod comparisons reveal how location preferences shifted with establishment of the RWP, while the second and third periods show how participation and the value of conservation agreements changed after listing. Table 1 presents total RWP enrollment and nonenrollment numbers during these three periods.

I now develop a discrete choice model to measure the effect of habitat quality on companies' drilling locations and their willingness to enroll wells in the RWP. Companies' preferences are a function of profitable location attributes and conservation values (with respect to habitat), as in the conceptual model. For simplicity, consider the location choice problem before the RWP. Using the structure of the conceptual model, expected value to company $i$ of drilling in location $j$ at time $t$ is:

$$
v_{i j t 0}=\alpha h_{j}+\beta x_{j}+\varphi_{j}+\varepsilon_{i j t 0}
$$

where $h_{j}$ is a dummy variable that equals one if the location is in the EOR +10 and zero otherwise, $x_{j}$ is a vector of other location attributes, $\phi_{j}$ is a vector of county fixed effects, and $\varepsilon_{i j t 0}$ is a random error term. The county fixed effects proxy the conceptual model's fixed cost $c_{j}$. Equation 2 does not contain any other terms from equation 1 because it is based on drilling in period 1 , before the RWP, which by definition has $k=0$ and $\delta_{t}=0$.

Now consider the choice problem when companies could participate in the RWP, in periods 2 and 3. Expected value depends on the choice to enroll in a conservation agreement or not. The expected value from an enrolled well (i.e.

Table 1. Number of oil and gas wells drilled by location, RWP status, and when drilling began

\begin{tabular}{lcccr}
\hline & \multicolumn{3}{c}{ Location and RWP enrollment status } \\
\cline { 2 - 5 } Period drilling began & $\begin{array}{c}\text { Not in } \\
\text { EOR }+\mathbf{1 0}\end{array}$ & $\begin{array}{c}\text { In EOR }+\mathbf{1 0} \text {, not } \\
\text { in RWP }\end{array}$ & $\begin{array}{c}\text { In EOR }+\mathbf{1 0} \text {, and } \\
\text { in RWP }\end{array}$ & Total \\
\hline $\begin{array}{l}\text { (1) Before RWP } \\
\begin{array}{c}\text { (2) During RWP, } \\
\text { candidate status }\end{array}\end{array}$ & 7,159 & 6,598 & 0 & 13,757 \\
$\begin{array}{c}\text { (3) During RWP, } \\
\text { threatened status }\end{array}$ & 1,412 & 976 & 31 & 2,419 \\
Total & 3,104 & 1,679 & 382 & 5,165 \\
\hline
\end{tabular}


$k=1$ ) is

$$
v_{i j t 1}=\alpha h_{j}+\beta x_{j}+\varphi_{j}+\kappa+\mu \ln \left(\mathrm{fee}_{j}\right)+\vartheta \bar{h}_{j}+\gamma_{\mathrm{esa}}+\eta_{i j}+\varepsilon_{i j t 1},
$$

where $\bar{h}_{j}$ is a decomposition of the habitat dummy into different habitat ranks, including focal areas, connectivity zones and other suitable habitat (the fourth rank, unsuitable habitat, is the reference category), $\kappa$ is the effect of the enrollment cost, which is a constant, fee ${ }_{j}$ is a location-specific mitigation fee, and $\eta_{i j}$ is an error component measuring firm-specific heterogeneity in the demand for conservation agreements. The effect of fee is largely identified from variation in ecoregion type because fee is a function only of ecoregion type, prior impacts and habitat rank, habitat rank is included as a variable $\left(\bar{h}_{j}\right)$, and existing impacts may be partially captured through the other location attributes $\left(x_{j}\right)$. I expect that $\vartheta$ is positive and varies by habitat rank, e.g., companies prefer conservation agreements in focal areas to conservation agreements in unsuitable habitat. The RWP should be more valuable in focal areas because enrolling a project in these areas is more likely to help LPCs. It is also reasonable to expect that $\kappa$ and $\mu$ are negative, i.e. that companies prefer to combine the RWP with locations that have a lower enrollment fee. The term $\gamma_{\text {esa }}$ measures the effect of listing on recruitment into the RWP in period 3, i.e., when $t=$ esa. This effect should be positive if enforcing ESA regulations incentivized participation in conservation agreements.

The expected value from drilling but not enrolling in the RWP (i.e. $k=0$ ) is

$$
v_{i j t 0}=\alpha h_{j}+\beta x_{j}+\varphi_{j}+\left(\delta_{\mathrm{rwp}}+\delta_{\mathrm{esa}}\right) h_{j}+\varepsilon_{i j t 0},
$$

where the effect of regulatory scrutiny $\delta_{t}$ in habitat locations varies across periods such that $t=\operatorname{rwp}$ in period 2 and $t=$ esa in period 3. Equation 4 differs from equation 3 because projects that do not enroll in the RWP experience this scrutiny but do not experience any conservation agreement costs/benefits. The first term in parentheses measures the effect of the RWP on drilling in habitat, while the second term measures the effect of ESA regulations (listing the LPC) on drilling in habitat. The second coefficient, $\delta_{\text {esa, }}$ will be negative if ESA regulations impose land use restrictions on projects not in the RWP. The sign of the first coefficient, $\delta_{\text {rwp }}$, is not clear ex ante; the RWP published detailed habitat maps, and the coefficient will be positive if this information attracted drilling into the habitat area (but that did not enroll in the RWP) and negative if it deterred companies from drilling in habitat.

Figure 1 presents a diagram of the empirical, discrete choice model. The top panel shows the choice alternatives before the RWP, when companies made location decisions using equation 2. The bottom panel shows the choice alternatives during the RWP, when companies made decisions using equations 


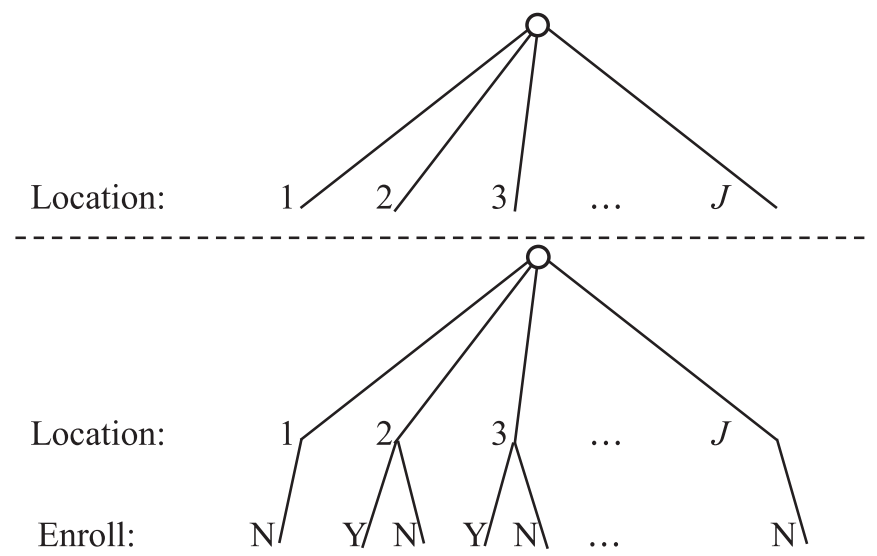

Figure 1. The choice model before availability of the RWP (top panel) and during the availability of the RWP (bottom panel). Locations outside the habitat area, such as locations 1 and $J$ in the diagram, did not have the enrollment option.

3 and 4. Each habitat location has two choice alternatives during the RWP: an enroll alternative and a not-enroll alternative.

I estimate two versions of the model. First, I fix $\eta_{i j}$ at zero and assume $\varepsilon_{i j t k}$ is independent and identically distributed extreme value for a conditional logit. The probability of choosing location $j$ and enrollment option $k$ from among all possible alternatives, i.e., $v_{i j t k}>v_{\text {imtl }}$ for all $m$ locations and $l$ enrollment options, is

$$
P_{i j t k}=e^{w_{i j t k}} / \sum e^{w_{\text {imtl }}}
$$

where $w_{i j t}$ is the observable, deterministic part of equations $2-4$. The logistic function is estimated using equation 2 for the choice occasions in period 1 , and equations 3-4 for the choice occasions in periods 2 and 3. I estimate all parameters simultaneously using maximum likelihood methods. Second, I assume $\eta_{i j}$ is an independent, normally distributed error component with standard deviation $\sigma$, to relax the independence of irrelevant alternatives (IIA) assumption and allow for flexible substitution patterns between the RWP and non-RWP alternatives (Hensher, Rose, and Greene 2005). Thus, the error component "nests" the RWP alternatives separately from the non-RWP alternatives. Then the probability of choosing alternative $j, k$ is

$$
P_{i j t k}=e^{w_{i t k}} / \sum e^{w_{\text {imtl }}} \phi(\eta \mid \sigma) d \eta,
$$

which is a mixed logit. I use the clogit routine in StataCorp Stata. Release 14 
(2014) to estimate the conditional logit and the mixlogit routine developed by Hole (2007) to estimate the mixed logit.

The analysis draws on two datasets. The first is oil and natural gas wells recorded by the Kansas and Oklahoma corporation commissions. I focus on these states because they contain the majority of LPC habitat and most participation in the RWP. ${ }^{3}$ Descriptive information includes the location, initial drilling date, completion date, geological formation targeted and if the well is producing oil, natural gas or both. I narrow the time series to January 2012 through May 2016 to focus on drilling around the time of the RWP and listing. For records missing the initial drilling date, I assume drilling began three months prior to completion, which is the typical length of time to complete a well in the study period. Following Melstrom (2017), I focus on drilling in western Kansas and Oklahoma based on corporation commission division boundaries. Location alternatives are described by Public Land Survey System (PLSS) coordinates, which subdivides land into a nested arrangement of quadrilaterals. Petroleum companies typically identify leases based on PLSS descriptions. Using the smallest spatial unit, the $1 \times 1$-mile section, there are nearly 100,000 location alternatives.

The second dataset comes from the list of petroleum projects participating in the RWP. I matched these projects to wells in the corporation commissions' database using project (well) names. Out of 838 enrolled projects, 49 percent match to a well. ${ }^{4}$ Unfortunately, it is impossible to tell if unmatched projects did not appear in commission records because companies decided not to complete the projects or were match failures because names did not harmonize across datasets. However, companies often delay drilling during periods of volatile and falling prices, which occurred at the end of the study period, making it likely that many of the unmatched projects never materialized (Kellogg 2014). I also collected spatial data on the RWP's habitat classifications and projected mitigation fees, which are commensurate with the quality of habitat impacted by the well (Van Pelt et al. 2013).

I drew a random sample of sections into the choice set to reduce the computational burden of estimating the model. Parsons and Kealy (1992) and Feather (1994) show that randomly sampling alternatives does not generate bias in problems with large choice sets. This procedure is based on the recommendation of McFadden (1978) for handling discrete choice problems with thousands of alternatives. For each choice occasion I randomly drew 249 sections without replacement, excluding those classified as primarily surface water. I then added the chosen section to the sample to

\footnotetext{
3 The other states with habitat are Colorado, New Mexico, and Texas. Companies drilled more wells in these states than in Kansas and Oklahoma-the ratio is about 1:4, based on drilling rig counts. However, the enrollment rate in Kansas and Oklahoma is higher: $56 \%$ of habitat and $60 \%$ of enrolled wells are in Kansas and Oklahoma.

4 Nine wells matched to RWP records but located outside habitat were dropped.
} 
yield 250 alternatives. These alternatives became the choice set for wells drilled before the RWP. I expanded number of alternatives after the launch of the RWP, by adding an enrollment option for each section in the EOR +10 , doubling the number of choice alternatives associated with the habitat locations.

Table 2 provides a description and summary statistics for each choice attribute in the model. The first set of attributes describes habitat locations, the second set describes the location of existing land uses, and the third set describes features of the RWP. In particular, habitat is a dummy that equals one for sections in habitat and zero otherwise; focal, connectivityzone, and suitable are dummies for each habitat rank. These three areas are a priority for habitat conservation. The means of these dummies imply that 46 percent of sections are in habitat, with 11 percent in focal areas, 2 percent in connectivity zones, and 14 percent in other suitable habitat. The dummies pasture, crops, wetlands, and developed equal one if pasture, crop farming, wetlands, or housing, respectively, is the primary land use in a section. These data show that 50 percent of locations in the study region are pasture, 41 percent are crops, less than 1 percent are wetlands, and 2 percent are primarily housing (the balance, 7 percent, is in forest). The variable fee is the average projected mitigation fee per acre to drill a well and participate in the RWP. ${ }^{5}$

I allow drilling activity in the model to be correlated over time and space in two ways. First, wells on the same lease are unlikely to be drilled independently of each other, so I cluster standard errors by petroleum lease. Second, companies may tend to cluster wells in locations with proven petroleum reserves. I therefore include the variable well $_{\text {dum }}$, to indicate which sections have existing wells, and well $s_{\text {num }}$, to measure the number of existing wells in a section prior to each choice occasion. Another possible concern is that the choice set definition developed above is too broad and includes irrelevant and insignificant alternatives. I probe the sensitivity of the results to a narrower choice set definition by restricting each company's choice set to sections in counties in which the company has one or more existing wells (as a company probably does not own or lease any land in counties it has not worked in before).

5 The mitigation fee depends on ecoregion, previous development impacts, and the RWP habitat ranks. Companies and individuals can use the RWP map, available online at https://kars.ku.edu/ geodata/maps/sgpchat/, to locate habitat, identify habitat ranks, and estimate mitigation fees. Actual mitigation fees may differ from those estimated by the mapping tool following a project review by RWP specialists. I use the average estimated fees in a section rather than actual fees paid because the latter are somewhat endogenous. In practice, projects enrolled in the RWP can reduce associated mitigation fees by locating in the areas of a section with less desirable ecosystem characteristics or habitat disturbed by previous development. 
Table 2. Location and RWP attributes in the choice models

\begin{tabular}{|c|c|c|c|}
\hline Attribute & Description & Mean & St. Dev. \\
\hline \multicolumn{4}{|c|}{ Habitat attributes $\left(h_{j}\right.$ and $\left.\bar{h}_{j}\right)$} \\
\hline habitat & $\begin{array}{l}\text { Dummy for sections in the } \\
\text { EOR }+10 \text { region }\end{array}$ & 0.463 & 0.499 \\
\hline focal & $\begin{array}{l}\text { Dummy for sections primarily } \\
\text { in focal areas }\end{array}$ & 0.112 & 0.270 \\
\hline connectivityzone & $\begin{array}{l}\text { Dummy for sections primarily } \\
\text { in connectivity zones }\end{array}$ & 0.020 & 0.105 \\
\hline suitable & $\begin{array}{l}\text { Dummy for sections primarily } \\
\text { in other suitable habitat }\end{array}$ & 0.137 & 0.273 \\
\hline \multicolumn{4}{|c|}{ Other location attributes $\left(x_{j}\right)$} \\
\hline refinerydistance & $\begin{array}{l}\text { Distance from section to nearest } \\
\text { oil refinery for oil wells (in } \\
\text { miles) }\end{array}$ & 39.46 & 58.10 \\
\hline gasplants & $\begin{array}{l}\text { Density of natural gas } \\
\text { processing plants in county } \\
\text { for gas wells (plants } / \text { mile }^{2} \text { ) }\end{array}$ & 0.047 & 0.370 \\
\hline$w_{\text {ells }} s_{\mathrm{dum}}$ & $\begin{array}{l}\text { Dummy for the presence of } \\
\text { wells in the section at time } \\
\text { drilling started }\end{array}$ & 0.003 & 0.057 \\
\hline$w_{\text {ells }}$ num & $\begin{array}{l}\text { Number of existing wells in the } \\
\text { section at time drilling } \\
\text { started }\end{array}$ & 0.008 & 0.228 \\
\hline pasture & Dummy for sections in pasture & 0.504 & 0.500 \\
\hline crops & Dummy for sections in crops & 0.412 & 0.492 \\
\hline wetlands & $\begin{array}{l}\text { Dummy for sections that are } \\
\text { wetlands }\end{array}$ & 0.002 & 0.044 \\
\hline developed & $\begin{array}{l}\text { Dummy for sections that are } \\
\text { developed (urban) }\end{array}$ & 0.022 & 0.148 \\
\hline transtensional & $\begin{array}{l}\text { Dummy for sections overlaying } \\
\text { transtensional basins }\end{array}$ & 0.451 & 0.498 \\
\hline sag & $\begin{array}{l}\text { Dummy for sections overlaying } \\
\text { sag basins }\end{array}$ & 0.143 & 0.350 \\
\hline \multicolumn{4}{|l|}{ RWP variables } \\
\hline enroll & $\begin{array}{l}\text { Dummy for RWP alternatives; } \\
\text { this variable identifies } \kappa \text { in } \\
\text { model }\end{array}$ & 0.024 & 0.153 \\
\hline fee & $\begin{array}{l}\text { Average cost per acre of } \\
\text { enrolling in RWP }\end{array}$ & 271.9 & 540.4 \\
\hline \multicolumn{4}{|c|}{ Time-specific variables } \\
\hline rwp & $\begin{array}{l}\text { Dummy for choice occasions } \\
\text { during RWP; } r w p \cdot h_{j} \text { to } \\
\text { identifies } \delta_{\text {rwp }} \text { in model }\end{array}$ & 0.434 & 0.496 \\
\hline
\end{tabular}


Table 2. Continued

\begin{tabular}{cccc}
\hline Attribute & Description & Mean & St. Dev. \\
\hline esa & $\begin{array}{c}\text { Dummy for choice occasions } \\
\text { when LPC listed, esa. } h_{j} \\
\text { identifies } \delta_{\text {esa }} \text { in model } \\
\text { Number of choice occasions }\end{array}$ & 0.296 & 0.456 \\
Wells drilled & & 21,341 \\
\hline
\end{tabular}

\section{Results}

The results show that companies generally avoid conservation agreements, except for a fraction of projects in priority habitat (lower panel of Table 3). Consider the conditional logit coefficients first, which, although subject to IIA, are similar to the mixed logit coefficients. The constant in the RWP value function is negative $(p<0.01)$, which means that companies are significantly more likely to not enroll than enroll a well in a conservation agreement. The effect of fee is also negative $(p<0.01)$, which implies that the probability of enrolling diminishes as the mitigation fee increases. We can interpret the coefficient as an elasticity, which implies that a 10 percent increase in fees reduces the number of enrollments by 1.3 percent. $^{6}$ However, the effect of the fee is small relative to the constant; at the maximum projected fee, the effect is $-0.128 \times \ln$ (3409) $=-1.038$, which is about one-fourth the size of the constant. This means that fixed costs are the primary deterrent to demand for RWP agreements. The effects of focalarea, connectivityzone, and othersuitablehabitat are all positive $(p<0.01)$, implying that companies are more likely to participate in the RWP if they prefer to drill in those areas relative to other parts of the EOR +10 . Conditional on fees, companies are most likely to enroll a project that they locate in a connectivity zone, although fees are low enough that even unconditionally companies tend to prefer enrolling in connectivity zones.

The error component in the mixed logit indicates significant heterogeneity in companies' willingness to enroll in the RWP. The estimated distribution of the RWP constant has a mean of -6.603 and standard deviation of 2.592, meaning that the vast majority of projects in the EOR +10 could not be induced to enroll in conservation agreements, even in focal areas and connectivity zones. For example, the model predicts 2 percent of companies would enroll a well if the location was a focal area with a $\$ 500 /$ acre mitigation fee when the LPC was a listing candidate.

6 The elasticity is $\partial E\left[n_{j}\right] / \partial \mathrm{fee}_{j} \times \mathrm{fee}_{j} / E\left[n_{j}\right]$ where $n_{j}$ is the number of wells at site $j$. The elasticity simplifies to $\mu\left(1-P_{j}\right)$ where $P_{j}$ is the probability of choosing $j$. This derivation is available from the author upon request. The elasticity is approximately $\mu$ because $P_{j t}$ rounds to zero at two decimal places. 
Table 3. Choice model coefficients

\begin{tabular}{|c|c|c|c|c|}
\hline \multirow[b]{2}{*}{ Coefficient } & \multicolumn{2}{|c|}{ Conditional logit } & \multicolumn{2}{|c|}{ Mixed logit } \\
\hline & Coef. & St. Err. & Coef. & St. Err. \\
\hline \multicolumn{5}{|c|}{ Location attributes } \\
\hline Habitat $(\alpha)$ & $0.183^{* *}$ & 0.048 & $0.181^{* *}$ & 0.038 \\
\hline $\operatorname{rwp}\left(\delta_{\text {rwp }}\right)$ & $-0.302^{* *}$ & 0.058 & $-0.302^{* *}$ & 0.054 \\
\hline esa $\left(\delta_{\mathrm{esa}}\right)$ & $-0.181^{* *}$ & 0.070 & $-0.191^{* *}$ & 0.066 \\
\hline refinerydistance & $0.003^{* *}$ & 0.0004 & $0.003^{* *}$ & 0.0003 \\
\hline gasplants & $0.201^{* *}$ & 0.023 & $0.201^{* *}$ & 0.022 \\
\hline wells $_{\mathrm{dum}}$ & $5.746^{* *}$ & 0.032 & $5.746^{* *}$ & 0.027 \\
\hline wells $_{\text {num }}$ & $0.040^{* *}$ & 0.010 & $0.041^{* *}$ & 0.006 \\
\hline pasture & 0.039 & 0.048 & 0.039 & 0.040 \\
\hline crops & 0.074 & 0.051 & $0.073^{*}$ & 0.042 \\
\hline wetlands & -0.161 & 0.189 & -0.159 & 0.185 \\
\hline developed & -0.085 & 0.084 & -0.085 & 0.071 \\
\hline transtensional & $0.113^{* *}$ & 0.052 & $0.111^{* *}$ & 0.040 \\
\hline $\operatorname{sag}$ & 0.076 & 0.053 & $0.073^{* *}$ & 0.045 \\
\hline \multicolumn{5}{|c|}{ RWP attributes } \\
\hline constant $(\kappa)$ & $-4.095^{* *}$ & 0.295 & $-6.603^{* *}$ & 0.479 \\
\hline error component ( $\eta$ ) & & & $2.541^{* *}$ & 0.247 \\
\hline $\ln ($ fee $)(\mu)$ & $-0.128^{* *}$ & 0.042 & $-0.134^{* *}$ & 0.037 \\
\hline focalarea & $1.341^{* *}$ & 0.229 & $1.283^{* *}$ & 0.231 \\
\hline connectivityzone & $2.696^{* *}$ & 0.303 & $2.722^{* *}$ & 0.303 \\
\hline othersuitablehabitat & $1.452^{* *}$ & 0.242 & $1.453^{* *}$ & 0.229 \\
\hline esa $\left(\gamma_{\mathrm{esa}}\right)$ & $1.775^{* *}$ & 0.210 & $2.415^{* *}$ & 0.264 \\
\hline County effects & & Yes & & Yes \\
\hline Log-likelihood & & -74621.695 & & -74541.511 \\
\hline Observations & & $5,687,287$ & & $5,687,287$ \\
\hline
\end{tabular}

Standard errors are clustered on lease. ${ }^{* *}$ and * denote statistical significance at the 0.05 and 0.10 levels, respectively. The regressions include a dummy for the timing of the proposed listing, but the coefficient was not significant.

The model shows that the timing of the RWP and ESA listing affected companies' location preferences. The effect of RWP among the general location attributes (upper panel, Table 3 ) is negative $(p<0.01)$, which indicates that companies became less likely to drill in the EOR +10 during the RWP. Specifically, based on the conditional logit estimates, about 2.4 percent of wells shifted away from the habitat area due to the RWP. The effect of ESA among 
the general location attributes is also negative, which indicates that companies became even less likely to drill in the EOR +10 once regulators listed the LPC. I also included an ESA indicator for the listing among the RWP alternatives. The coefficient on this indicator shows that listing had a positive effect $(p<$ 0.01) on enrollments, which means listing increased the value of participating in a conservation agreement. The mixed logit predicts 2 percent of projects in habitat would enroll in the RWP before listing but predicts 7 percent of projects would enroll under the same conditions after listing. The boost in demand for conservation agreements offsets the downward effect of listing on the desirability of habitat locations, so the model estimates listing had little overall effect on the rate of drilling in habitat.

An important concern is that the results are biased because the choice set includes too many irrelevant alternatives. I revised the selection of alternatives to probe the sensitivity of the results to choice set misspecification. Table 4 shows the coefficients when the choice set excludes alternatives in counties in which a company never drilled a well. In both the conditional logit and the mixed logit, the effects of the constant and fee in the panel of RWP attributes are negative $(p<0.01)$ - specifically, the latter indicates that a 10 percent increase in fees is associated with a 1.2 percent decline in enrollments-and the effects of focalarea, connectivityzone and othersuitablehabitat are all positive $(p<0.01)$. This indicates that companies dislike the cost of RWP agreements but are more likely to enroll when they locate projects in priority habitat. The coefficients in Table 4 are not appreciably different from those in Table 3, which implies that choice set misspecification is not a significant problem.

\section{Discussion and Conclusion}

This study showed that petroleum companies strongly preferred to keep their wells out of conservation agreements. The vast majority of projects in habitat went ahead without regulatory assurances, despite concerns raised about the potential cost of ESA regulations. Most of this avoidance was due to the fixed costs of participating in conservation agreements. Many companies must have viewed the legal cost and mitigation actions required for an agreement to be too onerous relative to the value of regulatory assurances.

This study also showed that industry responded to conservation incentives by shifting where development occurred or paying for mitigation. The RWP published an online mapping tool to help companies identify priority habitat in the EOR +10 . Companies were less willing to drill in the EOR +10 after the RWP was developed, which suggests some used the map to avoid damaging habitat. From an industry perspective, this behavior is desirable because it conserves habitat without costly conservation agreements, and lowers the expected cost of ESA regulations by reducing the chance of listing in the future. The map did not deter most projects, but it may have encouraged some of these to enroll in conservation agreements. Furthermore, project participation is significantly associated with locating a well in an area 
Table 4. Choice model coefficients from the restricted choice set

\begin{tabular}{|c|c|c|c|c|}
\hline \multirow[b]{2}{*}{ Coefficient } & \multicolumn{2}{|c|}{ Conditional logit } & \multicolumn{2}{|c|}{ Mixed logit } \\
\hline & Coef. & St. Err. & Coef. & St. Err. \\
\hline \multicolumn{5}{|c|}{ Location attributes } \\
\hline Habitat $(\alpha)$ & $0.215^{* *}$ & 0.051 & $0.216^{* *}$ & 0.045 \\
\hline $\operatorname{rwp}\left(\delta_{\text {rwp }}\right)$ & $-0.191^{* *}$ & 0.082 & $-0.191^{* *}$ & 0.079 \\
\hline esa $\left(\delta_{\text {esa }}\right)$ & $-0.448^{* *}$ & 0.100 & $-0.475^{* *}$ & 0.096 \\
\hline refinerydistance & -0.001 & 0.0005 & -0.001 & 0.0005 \\
\hline gasplants & $0.061^{*}$ & 0.037 & $-0.063^{*}$ & 0.035 \\
\hline wells $_{\mathrm{dum}}$ & $5.599^{* *}$ & 0.064 & $5.604^{* *}$ & 0.059 \\
\hline wells $_{\text {num }}$ & 0.018 & 0.021 & 0.019 & 0.018 \\
\hline pasture & 0.071 & 0.050 & 0.072 & 0.047 \\
\hline crops & $0.111^{* *}$ & 0.052 & $0.111^{* *}$ & 0.050 \\
\hline wetlands & -0.337 & 0.232 & -0.334 & 0.218 \\
\hline developed & -0.093 & 0.089 & -0.091 & 0.085 \\
\hline transtensional & $0.154^{* *}$ & 0.054 & $0.153^{* *}$ & 0.045 \\
\hline sag & 0.134 & 0.056 & $0.171^{* *}$ & 0.051 \\
\hline \multicolumn{5}{|c|}{ RWP attributes } \\
\hline constant $(\mathrm{\kappa})$ & $-4.010^{* *}$ & 0.304 & $-6.015^{* *}$ & 0.435 \\
\hline error component $(\eta)$ & & & $2.138^{* *}$ & 0.202 \\
\hline $\ln ($ fee $)(\mu)$ & $-0.116^{* *}$ & 0.043 & $-0.112^{* *}$ & 0.042 \\
\hline focalarea & $1.292^{* *}$ & 0.235 & $1.266^{* *}$ & 0.253 \\
\hline connectivityzone & $2.707^{* *}$ & 0.325 & $2.809^{* *}$ & 0.339 \\
\hline othersuitablehabitat & $1.486^{* *}$ & 0.249 & $1.468^{* *}$ & 0.252 \\
\hline esa $\left(\gamma_{\text {esa }}\right)$ & $1.467^{* *}$ & 0.217 & $2.148^{* *}$ & 0.278 \\
\hline County effects & & Yes & & Yes \\
\hline Log-likelihood & & -36944.643 & & -36880.476 \\
\hline Observations & & 587,859 & & 587,859 \\
\hline
\end{tabular}

Standard errors are clustered on lease. ${ }^{* *}$ and * denote statistical significance at the 0.05 and 0.10 levels, respectively. The regressions include a dummy for the timing of the proposed listing, but the coefficient was not significant.

with a higher habitat quality ranking, particularly connectivity zones, which supports one of the goals of the RWP (Van Pelt et al. 2013). ${ }^{7}$ Thus, while

\footnotetext{
7 Thus, participants systematically chose different locations than nonparticipants. However, it is not clear if the RWP caused participants to change where they drilled, or if where companies drilled caused them to participate.
} 
participation in conservation agreements was low, impact minimization and mitigation occurred where it was most needed.

The timing of participation suggests that the decision to list the prairie chicken shifted the demand for conservation agreements. Some companies may have preferred to free-ride off the conservation efforts of others, or delay their participation until they learned more about conservation outcomes and ESA regulations. Thus, many more companies entered into conservation agreements to protect their liability and the species when regulators listed the LPC. For other ESA candidates, however, conservation agreement programs terminate when the species is listed (e.g., Candidate Conservation Agreements with Assurances). Presumably, participation would have been greater if companies thought listing would forfeit the opportunity to enroll in a conservation agreement.

These results have several important policy implications. First, fixed costs (i.e., transactions costs) can be a substantial deterrent to participation, so streamlining the enrollment process for conservation agreements may have a large effect on recruitment. Research on conservation banking programs in the United States has come to similar conclusions (Fox and Nino-Murcia 2005). Second, demand for regulatory assurances and thus VCAAs will be highest when companies believe their participation has consequences for a species' ESA listed status. For the lesser prairie chicken, most conservation agreements occurred when regulators listed the species. Otherwise, the threat of future ESA penalties may be too low to incentivize industry and landowners to change their behavior (Ferraro, McIntosh, and Ospina 2007, 256). Third, by identifying priority habitat areas, conservation planners can highlight where regulatory assurances are most valuable. This will encourage habitat conservation by increasing the demand for VCAAs and mitigating the impacts of development in priority areas.

\section{References}

Boyd, J., and R.S. Epanchin-Niell. 2017. "Private sector conservation investments under the Endangered Species Act: A guide to return on investment analysis." Resources for the Future Discussion Paper (17-11).

Brown, G.M., and J.F. Shogren. 1998. "Economics of the Endangered Species Act." Journal of Economic Perspectives 12(3): 3-20.

Byl, J.P. 2015. "Toward More Effective Endangered Species Regulation." PhD thesis, Vanderbilt University.

Drechsler, M., F. Watzold, K. Johst, and J.F. Shogren. 2010. "An Agglomeration Payment for Cost-Effective Biodiversity Conservation in Spatially Structured Landscapes." Resource and Energy Economics 32(2): 261-275.

Duke, J.M. 2004. "Participation in Agricultural Land Preservation Programs: Parcel Quality and A complex Policy Environment." Agricultural and Resource Economics Review 33 (1): 34-49.

Feather, P.M. 1994. "Sampling and Aggregation Issues in Random Utility Model Estimation." American Journal of Agricultural Economics 76(4): 772-780. 
Ferraro, P.J., C. McIntosh, and M. Ospina. 2007. "The Effectiveness of the US Endangered Species Act: An Econometric Analysis Using Matching Methods." Journal of Environmental Economics and Management 54(3): 245-261.

Fox, J., and A. Nino-Murcia. 2005. "Status of Species Conservation Banking in the United States." Conservation Biology 19(4): 996-1007.

Hagen, C.A., B.E. Jamison, K.M. Giesen, and T.Z. Riley. 2004. "Guidelines for Managing Lesser Prairie-Chicken Populations and Their Habitats." Wildlife Society Bulletin 32(1): 69-82.

Hensher, D.A., J.M. Rose, and W.H. Greene. 2005. Applied Choice Analysis: A Primer. Cambridge University Press, Cambridge, UK.

Hole, A.R. 2007. "Fitting Mixed Logit Models by Using Maximum Simulated Likelihood." The Stata Journal 7(3): 388-401.

Innes, R., S. Polasky, and J. Tschirhart. 1998. "Takings, Compensation and Endangered Species Protection on Private Lands." Journal of Economic Perspectives 12(3): 35-52.

Kellogg, R. 2014. "The Effect of Uncertainty on Investment: Evidence from Texas Oil Drilling." American Economic Review 104(6): 1698-1734.

Langpap, C. 2004. "Conservation Incentives Programs for Endangered Species: An Analysis of Landowner Participation." Land Economics 80(3): 375-388.

- 2006. "Conservation of Endangered Species: Can Incentives Work for Private Landowners?" Ecological Economics 57(4): 558-572.

Langpap, C., and J. Wu. 2004. "Voluntary Conservation of Endangered Species: When Does No Regulatory Assurance Mean No Conservation?" Journal of Environmental Economics and Management 47(3): 435-457.

McFadden, D. 1978. "Modeling the Choice of Residential Location." Transportation Research Record 673: 72-77.

Mehmood, S.R., and D. Zhang. 2005. "Determinants of Forest Landowner Participation in the Endangered Species Act Safe Harbor Program." Human Dimensions of Wildlife 10(4): 249-257.

Melstrom, R.T. 2017. "Where to Drill? The Petroleum Industry's Response to an Endangered Species Listing." Energy Economics 66: 320-327.

Millennium Ecosystem Assessment. 2005. Ecosystems and Human Well-Being: Biodiversity Synthesis. Washington, DC: Island Press.

Naugle, D.E. 2011. Energy Development and Wildlife Conservation in Western North America. Washington, DC: Island Press.

Parkhurst, G.M., and J.F. Shogren. 2008. "Smart Subsidies for Conservation." American Journal of Agricultural Economics 90(5): 1192-1200.

Parkhurst, G.M., J.F. Shogren, C. Bastian, P. Kivi, J. Donner, and R.B.W. Smith. 2002. "Agglomeration Bonus: An Incentive Mechanism to Reunite Fragmented Habitat for Biodiversity Conservation." Ecological Economics 41(2): 305-328.

Parsons, G.R., and M.J. Kealy. 1992. "Randomly Drawn Opportunity Sets in a Random Utility Model of Lake Recreation." Land Economics 68(1): 93-106.

Reeling, C., L.H. Palm-Forster, and R.T. Melstrom. 2017. Policy Instruments, Strategic Interactions, and Incentives for Habitat Conservation for Imperiled Species. Poster presented at the 2017 meeting of the Agricultural and Applied Economics Association, No. 259157.

Shogren, J.F., J. Tschirhart, T. Anderson, A.W. Ando, S.R. Beissinger, D. Brookshire, G.M. Brown, D. Coursey, R. Innes, S. Meyer, and S. Polasly. 1999. "Why Economics Matters for Endangered Species Protection." Conservation Biology 13(6): 1257-1261.

Smith, R.B.W., and J.F. Shogren. 2002. "Voluntary Incentive Design for Endangered Species Protection." Journal of Environmental Economics and Management 43(2): 169-187.

StataCorp Stata. Release 14. 2014. Statistical Software. College Station, Texas, USA: StataCorp LP. Timmer, J.M., M.J. Butler, W.B. Ballard, C.W. Boal, and H.A. Whitlaw. 2014. "Spatially Explicit Modeling of Lesser Prairie-Chicken Lek Density in Texas." Journal of Wildlife Management 78(1): 142-152. 
U.S. Fish \& Wildlife Service. 1999. Endangered and Threatened Wildlife and Plants; Definition of Harm: 50 cfr Part 222. Washington, D.C.: Federal Register 64(215): 60727-60731.

- 2011. Candidate Conservation Agreements. Available at https://www.fws.gov/ endangered/esa-library/pdf/CCAs.pdf. (accessed 19 December 2016).

- 2013. Safe Harbor Agreements for Private Landowners. Available at https://www.fws. gov/endangered/esa-library/pdf/harborqa.pdf. Web (accessed 3 December 2017).

- 2014. "Endangered and Threatened Wildlife and Plants; Determination of Threatened status for the Lesser Prairie-Chicken." Washington, D.C.: Federal Register 79(69): 1997420071.

Van Pelt, W.E., S. Kyle, J. Pitman, D. Klute, G. Beauprez, D. Schoeling, A. Janus, and J. Haufler. 2013. "The lesser prairie-chicken rangewide conservation plan." Western Association of Fish and Wildlife Agencies. Cheyenne, Wyoming.

Wertz, J. 2015. Federal judge strips lesser prairie chicken of endangered species status, September 2015. Available at https://stateimpact.npr.org/oklahoma/2015/09/04/ federal-judge-strips-lesser-prairie-chicken-of-endangered-species-status/. StateImpact Oklahoma, NPR. 